\title{
Lung Transplantation and Endoscopic Issues
}

\author{
G. Callegari, C. Fracchia
}

Monaldi Arch Chest Dis 2011; 75: 1, 60-63.

Keywords: Lung transplantation, Bronchoscopy, Lung rejection, Lung infection, Airway complications.

Unità Operativa di Pneumologia Riabilitativa, Fondazione Salvatore Mangeri IRCCS, Istituto Scientifico di Montescano, Pavia.

Correspondence: Claudio Fracchia, Unità Operativa di Pneumologia Riabilitativa, Fondazione Salvatore Maugeri IRCCS, Istituto Scientifico di Montescano, Via per Montescano 31, 27040 Montescano (PV), Italy; e-mail: claudio.fracchia@fsm.it

In the last 20 years lung transplantation has become a therapeutic reality for many end-stage parenchymal and vascular lung diseases; despite the difficulty in finding donors, the results are currently satisfactory [1-3].

Infections, lung rejection and airway complications are the major causes of morbidity and mortality in patients who undergo lung or heartlung transplantation (LT) $[4,5]$. The usefulness of transbronchial lung biopsy (TLB) was reported for the first time in 1988 [6]. Since then TLB has become a routine practice in the management of patients who have undergone LT and still remains the "gold standard" for the diagnosis of rejection of a transplanted lung [7-11] Bronchoscopy with a flexible fibre-optic bronchoscope (FB), together with bronchoalveolar lavage (BAL) and TLB, have contributed significantly to the success of LT, being able to identify rejection and infections (bacterial, fungal, viral, protozoan) [12] (Evidence level: IIa).

\section{Recommendation}

- It is essential to perform FB in LT patients in order to diagnose rejection of the organ and pulmonary infections (Grade B).

BAL and TLB can be of surveillance or permormed when required by clinical and functional indications [9-11] (Evidence level: IIa).

\section{Recommendation}

- BAL and TLB must be carried out when clinically indicated and also at routine intervals (Grade B).

Furthermore, FB enables visualisation of the anastomosis and facilitates management of airway complications [12] (Evidence level: IIa).

\section{Recommendation}

- The status of the bronchial sutures must be monitored regularly in LT patients and their complications treated via FB (Grade B).

\section{Indications for bronchoscopy before a lung transplant}

The greatest hurdle to increasing the number of transplants performed is the low number of organs available; using the conventional criteria [4], one or both lungs of only $20 \%$ of donors can be used.

By allowing direct inspection of the donor's airways on the operating table, FB can be considered the final step in judging the suitability of the donor for LT [12]. Although it is not a common practice to carry out FB on a potential lung donor, when there is a suspicion that the tracheo-bronchial secretions of the donor have increased, a cleansing bronchoscopy must be performed. If the donor has borderline oxygenation for the donation, it should be taken into consideration that the oxygenation could improve after a cleansing bronchoscopy [12].

When a bronchoscopy is performed, BAL should be carried out for microbiological investigations, which could be useful after the transplant.

\section{Indications for bronchoscopy after a lung transplant}

\section{Procedure}

FB is usually carried out under local anaesthesia; many centres use a mild sedative. Given that FB is a routine procedure, often combined with TLB, sedation makes the procedure easier for the endoscopist as well as more comfortable for the patient who must undergo this procedure frequently [13].

\section{Pre-medication and sedation}

The endoscopist does not always use atropine; if this drug is used, it is administered 20-30 min- 
utes before the procedure. Although FB can be carried out without sedation $[14,15]$, a sedative is often given [16-18] since it enables the patient to stay calm and breath without difficulty even while the bronchoscope is in the airways. The drugs used are propofol, midazolam and fentanyl [19]; propofol is the drug of choice, although there are no randomised studies [12].

\section{Monitoring the patient}

During $\mathrm{FB}$, the $\mathrm{SaO}_{2}$ is monitored in order to determine whether oxygen is required and if so, its effects [13]; the ECG is also monitored, particularly in those patients with a history of arrhythmias and desaturations despite the use of oxygen [13]. It should be remembered that LT patients are at risk of desaturation for various reasons, including lung rejection and obstruction of the airways [20]. Some authors [12] recommend routine monitoring of the $\mathrm{SaO}_{2}$ and ECG, together with monitoring of the blood pressure. Routine transcutaneous $\mathrm{CO}_{2}$ measurements are not necessary.

\section{Broncho-alveolar lavage}

The technique of BAL in LT patients is the same as that in other patients. BAL is of great value in diagnosing, with high sensitivity and specificity $[21,22]$, bacterial, viral, fungal and protozoan infections. Microbiological and cytological techniques, immunohistological analyses, and molecular techniques such as polymerase chain reaction are used to diagnose pulmonary infections [12].

BAL is performed using normal physiological saline and samples of the lavage fluid are obtained for microbiological and cytological analyses [23]. The lavage fluid is obtained from both the perianastomotic area and the large airways (of the middle lobe and lingula); furthermore, samples are taken from any lung segments in which there is an inflammatory process. This procedure is repeated at the same intervals as TLB, but also more frequently in cases of suspected pulmonary infection and in immunocompromised patients such as a lung transplant recipients, since BAL is a less invasive technique than TLB [11].

\section{Transbronchial lung biopsy}

One of the most feared complications in the both the early and late periods after the operation is definitely rejection of the transplanted organ [24].

Acute rejection of a transplanted lung occurs most frequently in the first few months after the operation; the incidence is high in the first 100 days after the transplant, then drops but is not negligible [24]. The safest method for monitoring rejection remains TLB carried out at planned intervals, which can differ according to the protocol used, or when there are clinical and functional indications [9-11]. The relatively high incidence of silent acute rejection and/or infections found in asymptomatic patients has led to the use of planned surveillance TLB. Trulock et al. reported a high percentage of positive TLB carried out at 3 and 9 weeks and, subsequently at 6 and 12 months after LT; the rate of positive results in 90 surveillance TLB carried out in 43 patients was 57\% [9].

In order to optimise the diagnostic potential, the Lung Rejection Study Group recommends that at least five samples of lung parenchyma, each containing a minimum of 100 alveoli and bronchioles, are taken during each procedure [7-8]. The samples obtained are classified according to a scheme proposed by the "Working Formulation" of the International Society for Heart and Lung Transplantation [7, 8]. Endomyocardial biopsies were carried out routinely in the first patients who underwent heart-lung transplants: however, since rejection of the transplanted heart is extremely rare in these patients, this procedure has been abandoned [25].

The characteristic histological sign of acute lung rejection is a perivascular infiltration of leukocytes; the interstitium and alveoli are variously infiltrated and oedematous [7,8].

As far as regards chronic lung rejection, the characteristic histopathological finding is bronchiolitis obliterans [7, 8]. Activated lymphocytes cause the initial lesion to the bronchial epithelium with resulting necrosis and desquamation of the bronchial lumen. The accumulated debris is organized into granulation tissue forming concentric or eccentric plaques of collagen; alternatively it can completely block the lumen of the bronchioles. Further lesions of the small terminal bronchi predispose to the dilation of these latter, with the development of bronchiectasis; furthermore, bronchiolitis obliterans is associated with arteriosclerosis of the pulmonary vessels $[7,8]$

TLB does, however, have a poor sensitivity for diagnosing chronic lung rejection: in a series of 1235 TLB, the diagnosis of bronchiolitis obliterans was made in only 11 cases [11].

\section{Airway complications}

Although surgical techniques have improved and immunosuppressive strategies have been modified over the years, stenosis of the bronchial sutures and malacia remain frequent and feared complications of LT as a result of ischaemia at the suture site [26]. These are predominantly complications of the sutures of double lung transplants, whereas they are fairly rare following a single lung transplant or a heart-lung transplant. The frequency of complications of the anastomosis has decreased significantly in the last few years as a result of most recent surgical improvements and the development of new post-operative techniques [27, 28].

The reason why there is a higher incidence of suture complications in patients who have undergone double lung transplants is related to the precarious bronchial vascularization of the donor's lungs which, despite using a sequential technique of implantation, are exposed to long periods of ischaemia [29].

Most complications are related to necrosis of the suture which in turn, can evolve into stenosis, or in the worst of cases, into dehiscence; another 
feared complication is bronchomalacia which, from a therapeutic point of view is probably the most complex problem to resolve since it is not limited only to the anastomosis and surrounding tissues, but involves more extensive areas of the trachea and bronchi [30]. Since there is not a universally accepted classification of ischemic damage to the airways, some authors have proposed the TEGLA classification, an acronym for: Thickness, Extent of injury, Granulation tissue, Loose suture and Anastomotic/Airway complications [26] .

The treatment differs according to the type of complication and can be based on mechanical dilation of the anastomotic stenosis or may involve the use of a laser to achieve complete toilette of the stenosis $[23,31]$. When the complication cannot be resolved by using the previously described procedures, an endobronchial prosthesis (stent) must be placed with the aid of a rigid bronchoscope [3134]. Bronchial stents are silicon or metal that are positioned at the level of the anastomotic stenosis and left in situ permanently or for long enough for the bronchial wall to become more stable $[35,36]$.

\section{Complications of FB}

The complications associated with FB include hypoxia, bleeding, pneumothorax, pneumonia, respiratory depression, obstruction of the airways, cardio-respiratory arrest, arrhythmias, pulmonary oedema, vasovagal reactions and the development of pyrexia $[13,16,20]$. The mortality rate associated with FB ranges from 0.01 to $0.4 \%$ [16]; in a recent study carried out on 1235 TLB from patients with LT, there were no deaths related to the procedure [11].

\section{Summary of Recommendations}

- It is essential to perform FB in LT patients in order to diagnose rejection of the organ and pulmonary infections (Grade B).

- BAL and TLB must be carried out when clinically indicated and also at routine intervals (Grade B).

- The status of the bronchial sutures must be monitored regularly in LT patients and their complications treated via FB (Grade B).

\section{References}

1. Trulock EP, Edwards LB, Taylor DO, et al. Registry of the International Society for Heart and Lung Transplantation: Twenty-second Official Adult Report-2005. J Heart Lung Transplant 2005; 24: 956-967.

2. Studer SM, Levy RD, McNeil K, et al. Lung transplant outcomes: a review of survival, graft function, physiology, health-related quality of life, and cost-effectiveness. Eur Respir J 2004; 24: 674-685.

3. Nathan SD. Lung transplantation. Disease-specific consideration for referral. Chest 2005; 127: 1006-1016.
4. Trulock EP. Lung transplantation. Am J Respir Crit Care Med 1997; 155: 789-818.

5. Arcasoy SM, Kotloff RM. Lung Transplantation. New Engl J Med 1999; 340: 1081-1091.

6. Higenbottam T, Hutter JA, Stewart S, et al. Transbronchial lung biopsy for the diagnosis of rejection in heart-lung transplant patients. Transplantation 1988; 46: 532-539.

7. Cooper JD, Billingham M, Egan T, et al. A working formulation for the standardization of nomenclature and for clinical staging of chronic dysfunction in lung allografts. J Heart Lung Transplant 1993; 12: 713-716.

8. Yousem SA, Berry GJ, Cagle PT, et al. Revision of the 1990 Working Formulation for the classification of pulmonary allograft lung rejection: Lung Rejection Study Group. J Heart Lung Transplant 1996; 15: 1-15.

9. Trulock EP, Ettinger NA, Brunt EM, et al. The role of transbronchial lung biopsy in the treatment of lung transplant recipients: an analysis of 200 consecutive procedures. Chest 1992; 102: 1049-1054

10. Sibley RK, Berry GJ, Tazelaar HD, et al. The role of transbronchial biopsies in lung transplant recipients. $J$ Heart Lung Transplant 1993; 12: 308-324.

11. Hopkins PM, Aboyoun CL, Chhajed PN, et al. Prospective analysis of 1235 transbronchial lung biopsies in lung transplant recipients. J Heart Lung Transplant 2002; 21: 1062-1067.

12. Trulock EP. Flexible bronchoscopy in lung transplantation. Clinics in Chest Medicine 1999; 20: 77-87.

13. British Thoracic Society Bronchoscopy Guidelines Committee, a Subcommittee of Standards of Care Committee of British Thoracic Society. British Thoracic Society guidelines on diagnostic flexible bronchoscopy. Thorax 2001; 56 Suppl 1: i1-21.

14. Pearce SJ. Fiberoptic bronchoscopy: is sedation necessary? Br Med J 1980; 281: 779-780.

15. Colt HG, Morris JF. Fiberoptic bronchoscopy without premedication: a retrospective study. Chest 1990; 98: 1327-1330.

16. Simpson FG, Arnold AG, Purvis A, et al. Postal survey of bronchoscopic practice by physicians in the United Kingdom. Thorax 1986; 41: 311-317.

17. Prakash UB, Offord KP, Stubbs SE. Bronchoscopy in North America: the ACCP survey. Chest 1991; 100: 1668-1675.

18. Reed AP, Preparation of the patients for awake flexible fiberoptic bronchoscopy. Chest 1992; 101: 244-253.

19. Chhajed PN, Aboyoun CL, Malouf MA, et al. Progressive increase in sedative drug requirements for flexible bronchoscopy in lung transplant recipients. Am J Respir Crit Care Med 2003; 167: A529.

20. Chhajed PN, Aboyoun CL, Malouf MA, et al. Management of acute hypoxemia during flexible bronchoscopy with insertion of nasopharyngeal tube in lung transplant recipients. Chest 2002; 121: 1350-1354.

21. Malouf MA, Glanville AR. The spectrum of mycobacterial infection after lung transplantation. Am J Respir Crit Care Med 1999; 160: 1611-1616.

22. Tamm M, Malouf M, Glanville A. Pulmonary scedosporium infection following lung transplantation. Transpl Infect Dis 2001; 3: 189-194.

23. Chhajed PN, Tamm M, Malouf MA, et al. Lung transplantation: management and complication. Indian $J$ Chest Dis Allied Sci 2002; 44: 31-43.

24. Bando K, Paradis IL, Komatsu K, et al. Analysis of time dependent risk for infection, rejection and death after pulmonary transplantation. $J$ Thorac Cardiovasc Surg 1995; 109: 49-59.

25. McGregor CG, Baldwin JC, Jamieson SW, et al. Isolated pulmonary rejection after combined heart-lung transplantation. J Thorac Cardiovasc Surg 1985; 90: 623626. 
26. Chhajed PN, Tamm M, Glanville AR. Role of the flexible bronchoscopy in lung transplantation. Semin Resp Critic Care Med 2004; 26: 413-423.

27. Schafers HJ, Haydock DA, Cooper JD. The prevalence and management of bronchial anastomotic complications in lung transplantation. J Thorac Cardiovas Surg 1991; 101: 1044-1052.

28. Schmid RA, Boehler A, Speich R, et al. Bronchial anastomotic complications following lung transplantation: still a major cause of morbidity. Eur Respir J 1997; 10: 2872-2875.

29. Couraud L, Baudet E, Martigne C, et al. Bronchial revascularization in double lung transplantation: a series of 8 patients. Ann Thorac Surg 1992; 53: 88-94.

30. Shennib H, Massarb G. Airway complications in lung transplantation. Ann Thorac Surg 1994; 57: 506-511.

31. Chhajed PN, Malouf MA, Tamm M, et al. Interventional bronchoscopy for the management of airway complications following lung transplantation. Chest 2001; 120: 1894-1899.

32. Carre P, Rousseau H, Lombart L, et al. Balloon dilatation and self-expanding metal Wallstent insertion: for management of bronchostenosis following lung transplantation. The Toulouse Lung Transplantation Group. Chest 1994; 105: 343-348.

33. Chhajed PN, Malouf MA, Tamm M, et al. Ultraflex stents for the management of airway complications in lung transplant recipients. Respirology 2003; 8: 59-64.

34. Kapoor BS, May B, Panu N, et al. Endobronchial stent placement for the management of airway complication after lung transplantation. J Vasc Interv Radiol 2007; 18: 629-632.

35. Dumon JF. A dedicated tracheobronchial stent. Chest 1990; 97: 328-332.

36. Brichon PY, Blanc-Jourvan F, Rousseau H, et al. Endovascular stent for bronchial stenosis after transplantation. Transplant Proc 1992; 24: 2656-2659.

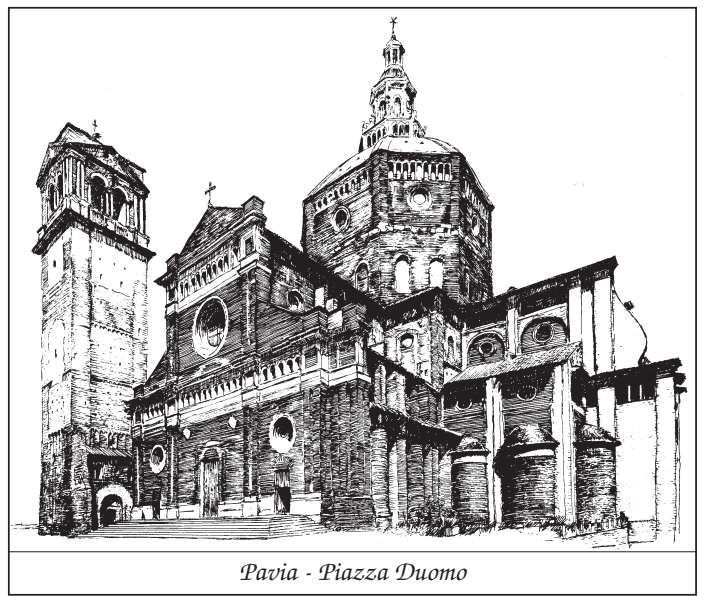

